\title{
Perancangan Sistem Pakar Diagnosis Penyakit Rematik Menggunakan Inferensi Forward Chaining Berbasis Prolog
}

\author{
Hairani, Mokhammad Nurkholis Abdillah, Muhammad Innuddin
}

Universitas Bumigora, Jl. Ismail Marzuki No. 22, Kota Mataram, 83127

\section{KEYWORDS}

Penyakit rematik, sitem pakar, forward

chaining, prolog

\section{CORRESPONDENCE}

Phone: 087839793970

E-mail: hairani@universitasbumigora.ac.id

\section{PENDAHULUAN}

Rematik adalah jenis penyakit yang sudah lama kita dengar. Rematik disebut juga arthritis atau radang sendi adalah penyakit yang menyerang sendi dan struktur atau jaringan penunjang di sekitar sendi. Kondisi rematik memiliki lebih dari 150 penyakit dan sindrom, yang biasanya progresif (tumbuh perlahan) dan berhubungan dengan nyeri [1]. Rematik yang paling sering diderita ada tiga jenis yaitu osteoarthritis, rheumatoid arthritis, dan arthritis gout [2] [3].

Kondisi rematik ini seringkali tidak disadari oleh masyarakat. Gejala yang paling umum adalah nyeri. Kecendrungan yang dilakukan masyarakat ketika merasakan gejala tersebut adalah dengan membeli obat-obatan untuk meredakan rasa sakit. Obat-obatan tersebut belum tentu cocok dan aman karena dari keadaan nyeri belum diketahui pasti penyebabnya. Dampak buruk dari kondisi rematik adalah kecacatan, sehingga menimbulkan biaya perawatan kesehatan yang sangat besar dan hilangnya pekerjaan [1].

Umumnya gejala-gejala pada kondisi rematik memiliki kemiripan dengan penyakit-penyakit pada tulang [4][5] (contohnya nyeri) sehingga sulit dibedakan. Salah satu solusi yang dapat digunakan yaitu pengembangan sistem pakar untuk diagnosis penyakit rematik. Sistem pakar adalah sistem berbasis komputer yang menggunakan pengetahuan, fakta dan teknik penalaran dalam memecahkan masalah yang biasanya hanya dapat dilakukan oleh seorang pakar [6].

Konsep dasar dari sistem pakar ini adalah memindahkan pengetahuan yang dimiliki oleh seorang pakar ke dalam program komputer. Pengetahuan yang dimodelkan dalam komputer nantinya akan ditelusuri berdasarkan gejala-gejala yang dialami pasien menggunakan teknik forward chaining. Teknik penalaran forward chaining (penelusuran maju) merupakan metode untuk menarik suatu kesimpulan berdasarkan fakta-fakta yang diperoleh [6].

Penelitian dibidang sistem pakar sudah banyak dilakukan, diantaranya dilakukan oleh [7] mengembangkan sistem pakar diagnosis penyakit diabetes menggunakan logika fuzzy. Metode logika fuzzy digunakan untuk memberikan persentase seseorang mengalami diabetes. Kelemahan penelitian ini adalah tidak menampilkan rule-rule yang terbentuk dari proses fuzzifikasi ke proses defuzzifikasinya.

Penelitian yang dilakukan oleh [8] merancang prototype diagnosis penyakit kronis berbasis sistem pakar. Perancangan prototypenya berfokus pada bagaimana merancang interface yang user-friendly. Kelemahan penelitian ini adalah tidak membahas metode inferensi yang digunakan.

Berdasarkan permasalahan diatas penelitian ini bertujuan untuk merancang sistem pakar diagnosis penyakit rematik menggunakan forward chaining berbasis prolog. Metode inferensi forward chaining digunakan untuk menarik 
kesimpulan jenis penyakit rematik yang diderita berdasarkan gejala-gejala yang dirasakan atau dimasukkan.

\section{METODOLOGI}

Dalam pembuatan sistem pakar diagnosis penyakit rematik berbasis sistem pakar menggunakana methdologi Expert System Development Life Cycle (ESDLC) yang tahapan-tahapannya seperti yang ditunjukkan pada Gambar 1.

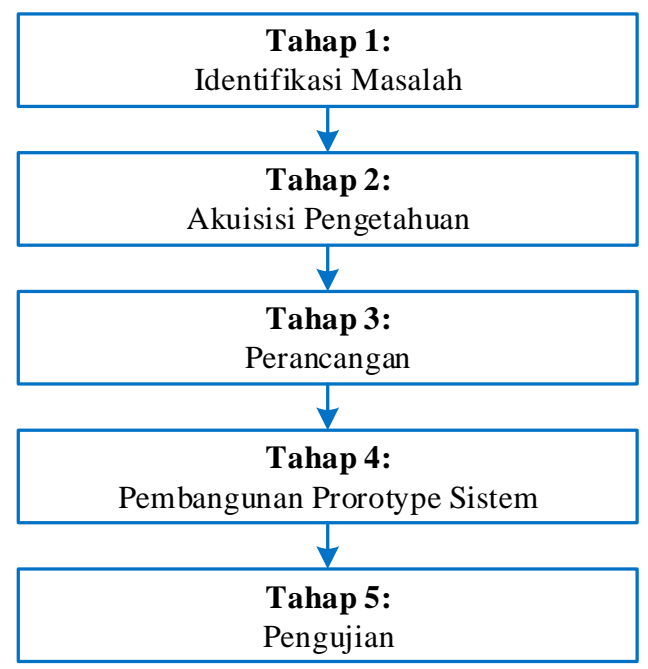

Gambar 1. Tahapan Penelitian

\section{Tahapan 1 : Identifikasi Permasalahan}

\section{Analisis Masalah}

Penyakit artrhitis atau sering dikenal dengan nama rematik merupakan penyakit yang menyerang sendi dan struktur atau jaringan penunjang sekitar sekitar sendi. Jenis penyakit rematik memiliki lebih dari 150 jenis, tetapi di indonesia ada 3 jenis penyakit paling sering diderita masyarakat diantaranya Gout Arhritis, Rhematoid Arthritis, dan Osteo Arthritis. Gejala pada jenis penyakit rematik sering tidak disadari oleh masyarakat, karena umumnya memiliki gejala-gejala yang mirip.

\section{Identifikasi Hak Akses}

Pengguna sistem memiliki hak akses yang berbeda pada sistem seperti yang ditunjukkan pada Tabel 1 .

Tabel 1. Hak Akses

\begin{tabular}{lll}
\hline User & Hak Akses \\
\hline Administrator & 1. & Akses Login \\
(Pakar) & 2. & Manajemen Data User \\
& 3. & Manajemen Data Penyakit \\
& 4. & Manejemn Data Gejala \\
& 5. & Manajemen Pasien \\
& 6. & Manajemen Penyebab Penyakit \\
& 7. & Manajemen Pengobatan Penyakit \\
& 8. & Manajemen Kaidah Produksi \\
& 9. & Manajemen Penelusuran \\
& 10. & Konsultasi \\
\hline Asisten Dokter & 1. & Akses Login \\
& 2. & Manajemen Data Pasien \\
& 3. & Konsultasi \\
\hline
\end{tabular}

\section{Tahapan 2 : Akuisisi Pengetahuan}

Tahapan akuisisi pengetahuan adalah proses untuk memperoleh pengetahuan dari seorang pakar yang digunakan sebagai basis pengetahuan dalam sistem pakar. Pengetahuan didapatkan menggunakan metode wawancara dengan dokter spesialis rematik di rumah sakit Graha Ultima Medika Mataram. Data hasil wawancara yang diperoleh adalah data jenis penyakit rematik beserta gejala-gejalanya. Jenis penyakit rematik diteliti sebanyak 3 jenis penyakit yaitu Gout Arthritis, Rhematoid Arthritis, dan Osteo Arthritis. Ketiga jenis penyakit tersebut diteliti karena sebagian besar masyarakat di indonesia mengalami 3 jenis penyakit tersebut.

\section{Tahapan 3 : Perancangan}

Tahapan perancangan merupakan proses untuk memodelkan data yang dikumpulkan pada tahap identifikasi masalah dan akuisisi pengetahuan kebentuk yang mudah dimengerti. Perancangan pada penelitian ini terdiri dari perancangan representasi pengetahuan, Use Case, dan Diagram Activity

\section{Perancangan Representasi Pengetahuan}

Perancangan representasi pengetahuan pada sistem pakar diperlukan untuk memodelkan data hasil akuisisi pengetahuan ke bentuk yang mudah dipahami yaitu bentuk model Tabel keputusan, Tabel keterangan gejala, Tabel Keterangan Penyakit, dan Pohon Keputusan masing-masing ditunjukkan pada Tabel 2, Tabel 3, Tabel 4, dan Gambar 2.

Tabel 2. Tabel Keputusan

\begin{tabular}{lccc}
\hline Kode Gejala & P001 & P002 & P003 \\
\hline G001 & $*$ & $*$ & $*$ \\
\hline $\mathbf{G 0 0 2}$ & $*$ & $*$ & $*$ \\
\hline $\mathbf{G 0 0 3}$ & $*$ & $*$ & $*$ \\
\hline $\mathbf{G 0 0 4}$ & $*$ & $*$ & $*$ \\
\hline $\mathbf{G 0 0 5}$ & $*$ & & $*$ \\
\hline $\mathbf{G 0 0 6}$ & $*$ & $*$ & $*$ \\
\hline $\mathbf{G 0 0 7}$ & & $*$ & $*$ \\
\hline $\mathbf{G 0 0 8}$ & & $*$ & \\
\hline
\end{tabular}

Tabel 3. Tabel Keterangan Gejala

\begin{tabular}{ll}
\hline Kode & \multicolumn{1}{c}{ Gejala } \\
\hline G001 & Nyeri Sendi \\
\hline G002 & Sendi kaku \\
\hline G003 & Sendi membengkak \\
\hline G004 & Tendapat benjolan di sendi \\
\hline G005 & Sendi kemerahan \\
\hline G006 & Perubahan bentuk pada sendi \\
\hline G007 & Adanya bunyi krek pada sendi digerakkan \\
\hline G008 & Tubuh mudah lelah \\
\hline
\end{tabular}

Tabel 4. Tabel Keterangan Penyakit

\begin{tabular}{ll}
\hline Kode & Jenis Penyakit \\
\hline P001 & Gout Arthritis \\
\hline P002 & Rhematoid Arthritis \\
\hline P003 & Osteo Arthritis \\
\hline
\end{tabular}




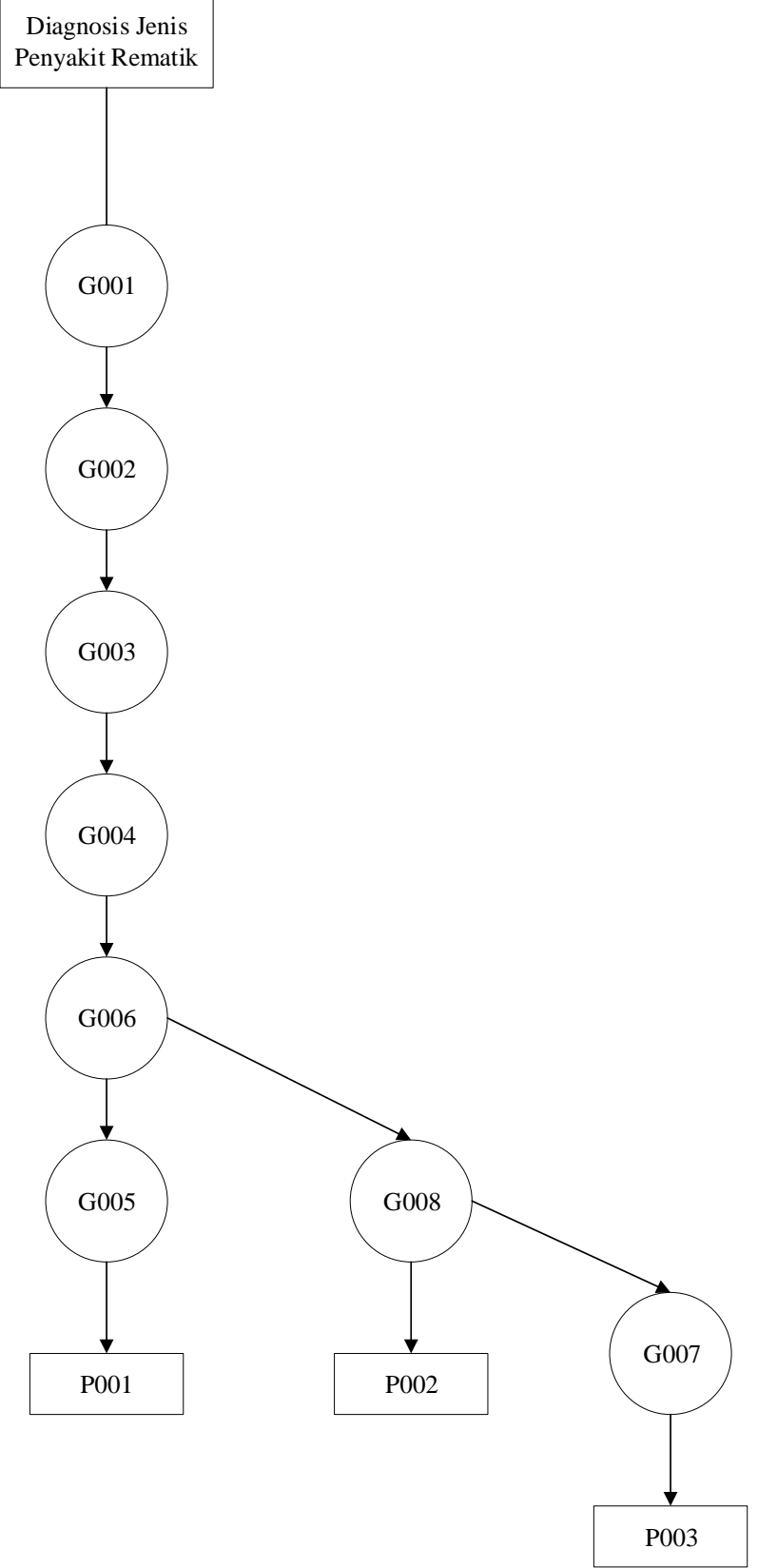

Gambar 2. Pohon Keputusan

\section{Kaidah Produksi (Basis Pengetahuan)}

Perancangan kaidah produksi (basis pengetahuan) digunakan untuk mambuat aturan-aturan yang disimpan sebagai basis data. Berikut kaidah produksi yang hasilkan berdasarkan dari Gambar 2.

Rule 1:

JIKA mengalami nyeri sendi (G001)

Dan Sendi Kaku (G002)

Dan Sendi Membengkak (G003)

Dan Terdapat benjolan di sendi (G004)

Dan Sendi Kemerahan (G005)

Dan Perubahan bentuk pada sendi (G006)

Maka kesimpulannya menderita penyakit Gout Arthritis ( P001).

Rule 2:

JIKA mengalami nyeri sendi (G001)

DAN Sendi Kaku (G002)
DAN Sendi Membengkak (G003)

DAN Terdapat benjolan di sendi (G004)

DAN Perubahan bentuk pada sendi (G006)

DAN Tubuh mudah lelah (G008)

Maka kesimpulannya menderita penyakit Gout Arthritis ( P002 ).

Rule 3:

JIKA mengalami nyeri sendi (G001)

DAN Sendi Kaku (G002)

DAN Sendi Membengkak (G003)

DAN Terdapat benjolan di sendi (G004)

DAN Perubahan bentuk pada sendi (G006)

DAN Adanya bunyi krek pada sendi digerakkan (G007)

DAN Tubuh mudah lelah (G008)

Maka kesimpulannya menderita penyakit Gout Arthritis ( P003 ).

\section{Perancangan Use Case}

Perancangan use case penelitian ini diperlukan untuk menjelaskan interaksi yang terjadi antara pengguna dan sistem. Pengguna sistem terdiri dari 2 user yaitu Administrator (Pakar) dan Asisten Dokter, masingmasing pengguna memiliki hak akses yang berbeda seperti yang ditunjukkan pada Gambar 3.

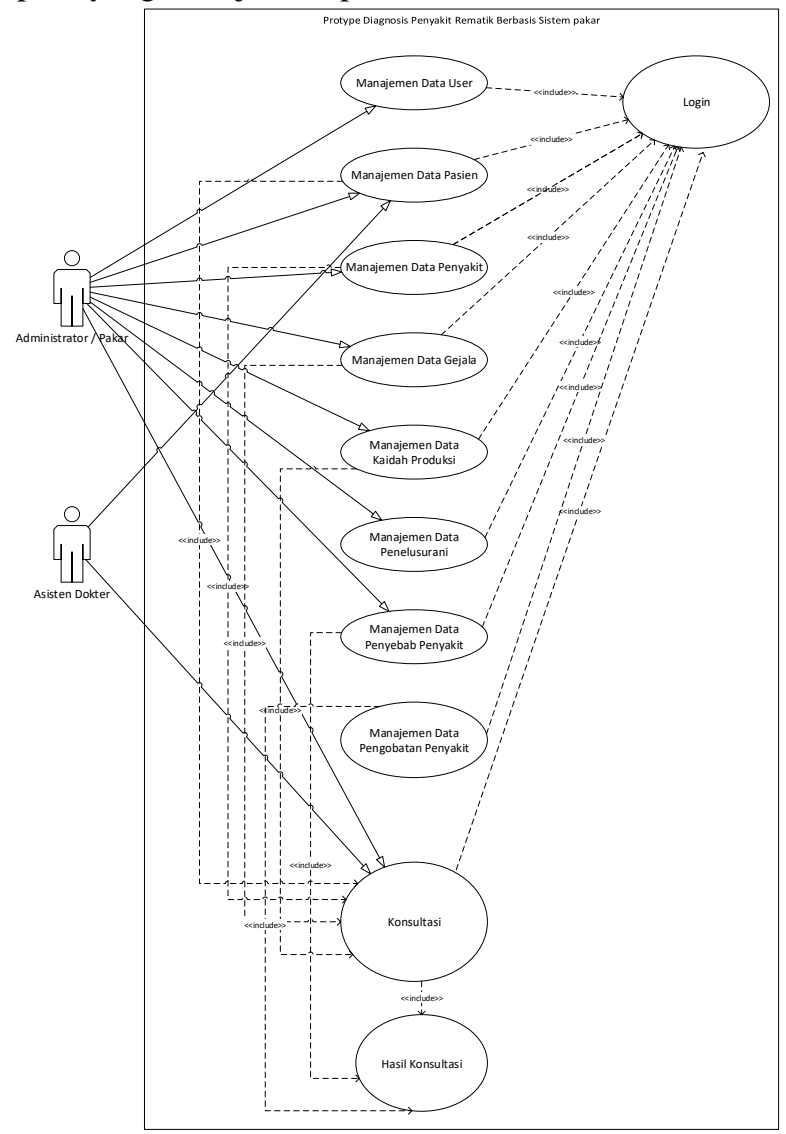

Gambar 3. Use Case Prototype Diagnosis Penyakit Rematik

\section{Perancangan Diagram Activity}

Perancangan activity diagram pada penelitian ini bertujuan untuk menggambarkan proses diagnosa penyakit rematik sampai menghasilkan hasil diagnosa berupa jenis penyakit rematik yang diderita seorang pasien dilakukan 
seorang asisten dokter. Activity diagram proses diagnosa penyakit jenis rematik ditunjukkan pada Gambar 4 .

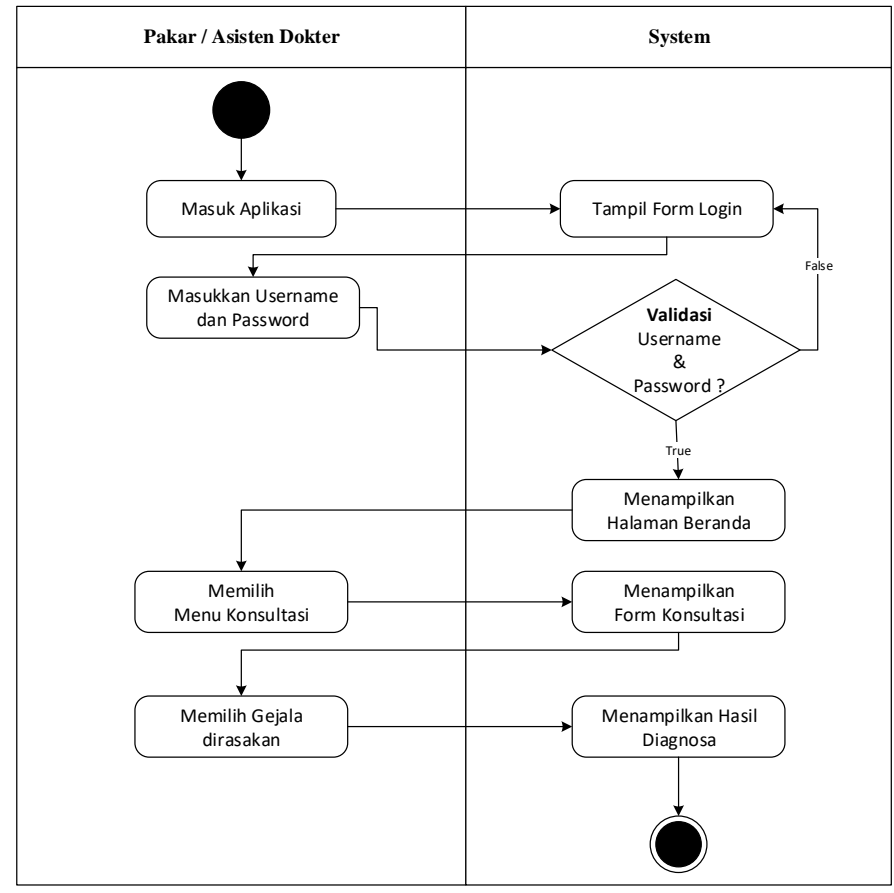

Gambar 4. Diagram Activity Proses Diagnosa

\section{Tahapan 4 : Pembangunan Prototype Sistem}

Pembuatan aplikasi prototype diagnosis jenis penyakit rematik pada penelitian ini menggunakan prolog. Pembuatan prototype bertujuan untuk menguji asumsi-asumsi mengenai bagaimana mengkodekan jenis penyakit rematik, gejala-gejala, relasi antar penyakit dan gejala, serta bagaimana inferensi forward chaining bekerja untuk menampilkan hasil diagnosa berdasarkan gejala yang dirasakan atau dimasukkan.

\section{HASIL DAN PEMBAHASAN}

Perancangan sistem pakar diagsosis jenis penyakit rematik dengan inferensi forward chaining menggunakan Prolog. Proses diagnosis jenis penyakit rematik dengan inferensi forward chaining, hanya perlu menjawab ya atau tidak berdasarkan gejala yang dirasakan seperti yang ditunjukkan pada Gambar 5.

SWI-Prolog (Multi-threaded, version 8.0.1)

File Edit Settings Run Debug Help

?- mulai

PROTOTYPE DIAGNOSIS PENYAKIT REMATIK BERBASIS SISTEM PAKAR MENGANALISA JENIS PENYAKIT REMATIK. .

Jawab pertanyaan berikut dengan y atau $t$

Apakah anda mengalami Nyeri Sendi?

Apaka

|: y.
|:

Gambar 5. Proses Diagnosa Penyakit Rematik

\section{Kasus pengujian :}

Seorang pasien mengalami gejala seperti dibawah ini:

Mengalami nyeri sendi (G001), sendi kaku (G002), sendi membengkak (G003), terdapat benjolan di sendi (G004), sendi kemerahan (G005), perubahan bentuk pada sendi (G006).
Berdasarkan kaidah produksi (basis pengetahuan) yang ada dapat disimpulkan bahwa pasien tersebut menderita penyakit Gout Arthritis ( P001 ).

Melakukan pengujian apakah hasil kasus pengujian sama dengan hasil menggunakan prolog dengan memasukkan gejala yang sama. proses diagnosa penyakit rematik dilakukan dengan cara mengklik tombol jawaban ya atau tidak berdasarkan gejala yang dirasakan. Hasil diagnosanya berupa jenis penyakit rematik yang diderita berdasarkan gejala yang ada pada kasus pengujian dan hasil doagnosanya seperti yang ditunjukkan pada Gambar 6.

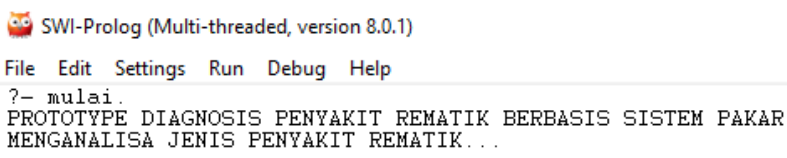

Gambar 6. Hasil Diagnosa Jenis Penyakit Rematik

\section{KESIMPULAN DAN SARAN}

Setelah dilakukan tahapan identifikasi masalah, akuisisi pengetahuan, perancangan, analisis, pembangunan prototype sistem, dan pengujian maka terdapat beberapa kesimpulan, diantaranya adalah sebagai berikut.

1. Perancangan sistem pakar diagnosis penyakit rematik menggunakan prolog dapat menyimpulkan hasil diagnosa berupa jenis penyakit rematik diderita pasien.

2. Penggunaan metode inferensi forward chaining sangat cocok diterapkan pada kasus ini, karena dapat menampilkan satu persatu gejala yang sesuai dirasakan oleh pasien.

Untuk penelitian selanjutnya dapat mengembangkan aplikasi sebenarnya baik berbasis web maupun mobile serta beberapa saran untuk penyempurnaan penelitian ini adalah sebagai berikut :

1. Penelitian ini hanya membuat prototype nya, sehingga kedepannya dapat dikembangakan ke sistem yang sebenarnya baik berbasis web ataupun mobile.

2. Pengembangan aplikasi kedepannya dapat mengkombinasikan metode inferensi forward chaining dan metode certainty factor untuk mendapat nilai kepastian jenis penyakit rematik yang diderita. 


\section{UCAPAN TERIMA KASIH}

Terima kasih saya ucapkan kepada DRPM DIKTI atas dukungannya berupa dana penelitian dalam skema penelitian dosen pemula sehingga penulis dapat melaksanakan penelitian ini.

\section{DAFTAR PUSTAKA}

[1] M. J. S. Corpuz, J. Avestro, F. B. Calanda, R. C. Morco, J. M. Angeles, and C. M. S. Alcala, "eRheumatologist: Mobile-based Expert System for Rheumatology Utilizing Fuzzy Logic Algorithm," in Proceedings of the 2017 International Conference on Computer Science and Artificial Intelligence, 2017, pp. 153-157.

[2] P. Utomo, Apresiasi penyakit: pengobatan secara tradisional dan modern. Jakarta: Rineka Cipta, 2005.

[3] O. Nainggolan, "Prevalensi dan determinan penyakit rematik di Indonesia," Maj. Kedokt. Indones., pp. 588594, 2009.

[4] S. Arlis, "Diagnosis Penyakit Radang Sendi Dengan Metode Certainty Factor," SATIN - Sains dan Teknol. Inf., vol. vol.3, no., pp. 42-47, 2017.

[5] A. Herliana, V. A. Setiawan, and R. T. Prasetio, "Penerapan Inferensi Backward Chaining pada Sistem Pakar Diagnosa Awal Penyakit Tulang," J. Inform., vol. vol.5, no, pp. 50-60, 2018.

[6] Kusrini, Sistem Pakar Teori dan Aplikasi. Yogyakarta: Andi, 2006.

[7] A. A. Abdullah, N. S. Fadil, and W. Khairunizam, "Development of Fuzzy Expert System for Diagnosis of Diabetes," in 2018 International Conference on Computational Approach in Smart Systems Design and Applications, ICASSDA 2018, 2018.

[8] S. H. Jabeen and G. Zhai, "A prototype design for medical diagnosis by an expert system," in 2017 7th International Workshop on Computer Science and Engineering, WCSE 2017, 2017, pp. 1413-1417.

\section{PROFIL PENULIS}

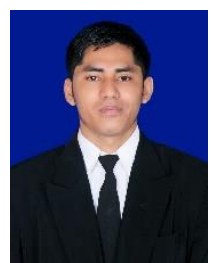

\section{Hairani}

Lulus S1 di Program Studi Teknik Informatika Fakultas Teknologi Informasi Universitas Islam Indonesia "UII" Yogyakarta Tahun 2014, lulus S2 pada Program Magister Teknik Elekto Konsentrasi Teknologi Informasi Universitas Gadjah Mada "UGM" Yogyakarta tahun 2017. Saat ini menjadi dosen pada prodi Ilmu Komputer di Universitas Bumigora Mataram.

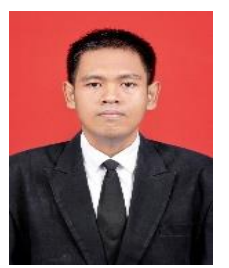

\section{Mokhammad Nurkholis Abdillah}

Lulus S1 di Program Studi Teknik Elektro Fakultas Teknik Universitas Negeri Semarang "UNNES" Yogyakarta Tahun 2010, lulus S2 pada Program Magister Teknik Elekto Konsentrasi Teknologi Informasi Universitas Gadjah Mada "UGM" Yogyakarta tahun 2016. Saat ini menjadi dosen pada prodi Ilmu Komputer di Universitas Bumigora Mataram.

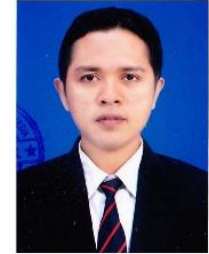

\section{Muhammad Innuddin}

Lulus S1 di Program Studi Teknik Informatika STMIK Syaikh Zainuddin Nahdlatul Wathan Tahun 2013, lulus S2 pada Program Magister Teknik Informatika Konsentrasi Digital Forensik Universitas Islam Indonesia "UII" Yogyakarta tahun 2017. Saat ini menjadi dosen pada prodi Ilmu Komputer di Universitas Bumigora Mataram. 